\title{
Comparison of benzoate- and dodecaborate-based linkers for attachment of radioiodine to HER2-targeting Affibody ligand
}

\author{
THUY TRAN ${ }^{1}$, ANNA ORLOVA $^{1,2}$, IGOR SIVAEV $^{3}$, MATTIAS SANDSTRÖM $^{4}$ and VLADIMIR TOLMACHEV ${ }^{1,2}$ \\ ${ }^{1}$ Division of Biomedical Radiation Sciences, Rudbeck Laboratory, Uppsala University, Uppsala; ${ }^{2}$ Affibody AB, \\ Bromma, Sweden; ${ }^{3}$ Nesmeyanov Institute of Organo-Element Compounds, Russian Academy of Sciences, \\ Moscow, Russia; ${ }^{4}$ Department of Hospital Physics, Uppsala University Hospital, Uppsala, Sweden
}

Received September 4, 2006; Accepted October 19, 2006

\begin{abstract}
The use of radionuclide molecular imaging enables the selection of patients for treatment using molecular medicine. Preclinical studies have demonstrated that a novel low-molecular-weight affinity ligand, Affibody molecule $\mathrm{Z}_{\text {HER2:342 }}$ can image the expression of HER2 with high sensitivity and specificity in tumour xenografts and has a potential for the selection of patients for treatment using Herceptin or other anti-HER2 medicine. In this study, we performed a comparative evaluation of two possible linkers for radioiodination of the Affibody molecule $\mathrm{Z}_{\mathrm{HER} 2: 342}$, 4-iodobenzoate (PIB) and [4-isothiocyanatobenzyl)-amino]undecahydro-closo-dodecaborate (DABI). It was shown that the use of DABI makes it possible to obtain radioiodinated $\mathrm{Z}_{\mathrm{HER} 2: 342}$ with preserved capacity for selective binding to HER2-expressing cells. There was no difference between ${ }^{125} \mathrm{I}_{-} \mathrm{PIB}-\mathrm{Z}_{\mathrm{HER} 2: 342}$ and ${ }^{125} \mathrm{I}-\mathrm{DABI}-\mathrm{Z}_{\mathrm{HER} 2: 342}$ in cellular retention of radioactivity after interrupted incubation with radiolabelled Affibody ligands. In vivo, the biodistribution of ${ }^{125} \mathrm{I}-$ PIB-Z $\mathrm{Z}_{\text {HER2:342 }}$ was characterized by a high tumour uptake at $4 \mathrm{~h}$ pi $(12.7 \pm 4.6 \% \mathrm{IA} / \mathrm{g})$ and a quick clearance from blood and normal organs. The tumour uptake of ${ }^{125} \mathrm{I}-\mathrm{DABI}-\mathrm{Z}_{\mathrm{HER} 2: 342}$ was appreciably lower $(2.7 \pm 1.2 \% \mathrm{IA} / \mathrm{g})$, and a high uptake of this conjugate in the liver was observed. A $\gamma$-camera experiment (at $6 \mathrm{~h} \mathrm{pi}$ ) demonstrated that the use of ${ }^{125}$ I-PIB$\mathrm{Z}_{\mathrm{HER} 2: 342}$ provided a much better contrast of imaging HER2expressing xenografts than the use of ${ }^{125} \mathrm{I}-\mathrm{DABI}-\mathrm{Z}_{\mathrm{HER} 2: 342}$. In conclusion, ${ }^{125} \mathrm{I}-\mathrm{PIB}-\mathrm{Z}_{\mathrm{HER} 2: 342}$ is superior to ${ }^{125} \mathrm{I}-\mathrm{DABI}-$ $\mathrm{Z}_{\mathrm{HER} 2: 342}$ as an agent for imaging HER2 expression in vivo.
\end{abstract}

Correspondence to: Dr Vladimir Tolmachev, Division of Biomedical Radiation Sciences, Rudbeck Laboratory, Uppsala University, S-751 85 Uppsala, Sweden

E-mail: vladimir.tolmachev@bms.uu.se

Key words: radionuclide molecular imaging, HER2, Herceptin

\section{Introduction}

The treatment of disseminated cancer is one of the main challenges of contemporary medicine. A common technique of systemic treatment is chemotherapy; however, indiscriminate toxicity limits the success of this approach. An alternative is tumour targeting, i.e. molecular recognition of gene products aberrantly expressed in cancer for delivery of cytotoxic substances to malignant cells.

One of the tumour-associated proteins, which is considered as promising for targeting is HER2, also known as erbB2 or neu. HER2 is a transmembrane protein belonging to the human epidermal growth factor tyrosine kinase receptor family. Increased HER2 activity is associated with increased proliferation and decreased apoptotic capacity. It is known that HER2 is expressed only to a small extent or not at all in normal adult tissues $(1,2)$. However, $25-30 \%$ of breast cancers (as well as ovarian cancers) demonstrate strong expression of HER2, and this expression is believed to be part of the formation of the malignant phenotype (3). For the moment, HER2-overexpressing breast tumours are treated using trastuzumab (Herceptin ${ }^{\circledR}$ ), a humanised anti-HER2 monoclonal antibody (4). Numerous trials have demonstrated the efficacy of trastuzumab, alone or preferably in combination with chemotherapy, for the treatment of breast cancer (5). New anti-HER2 targeting agents are emerging, such as humanised monoclonal antibody pertuzumab. Apparently, the detection of HER2 expression is crucial for the selection of anti-HER2 molecular therapy and is recommended for all patients with breast tumours both by the American Association of Clinical Oncology (6) and the European Group on Tumour Markers (7). For the moment, the main method, which is recommended for the determination of HER2, is immunohistochemistry (calibrated against FISH) of biopsy samples. This method, however, is associated with pitfalls, such as sampling errors due to the heterogeneity of HER 2 expression in the tumour. Targeting radionuclide diagnostics helps to avoid these problems by imaging the entire tumour in a single non-invasive procedure.

Radiolabelled natural ligands or their analogues are often used as imaging agents for the overexpression of receptors (8). However, this approach is not possible for HER2 since, so far, no natural ligand to HER2 has been identified, and it 
is believed that activation of the tyrosine kinase of HER2 is triggered by heterodimerisation with other members of the receptor family (9). For this reason the development of targeting agents for HER2 was based on radioimmunodetection. A notable study by Behr and co-workers (10) demonstrated that the use of radiolabelled trastuzumab predicts both patient response to trastuzumab and the major side effect, cardiotoxicity. Nevertheless, smaller targeting agents provided the advantage of a short time interval between tracer injection and imaging, and recent developments concentrated on smaller anti-HER2 antibody fragments, such as $\left(\mathrm{Fab}^{\prime}\right)_{2}(11)$, Fab (12), single chain Fv or their dimers (diabodies) (13) or minibody (14).

Recently, we reported on an approach, which makes it possible to create targeting agents smaller than the smallest antibody fragment, called Affibody ligands. This approach is a variant of phage display technique based on the Affibody technology which utilises the domain scaffold of the immunoglobulin-binding Staphylococcal receptor protein A. The 58-amino-acid-long cysteine-free Affibody protein provides a robust framework, independent of disulfide bonds for its folding. Randomization of 13 solvent-accessible surface residues of the protein A domain was used to create a library containing about $10^{9}$ members, enabling the isolation of high-affinity ligands for virtually any protein target (15). First generation anti-HER2 Affibody ligand, $\mathrm{Z}_{\text {HER } 2: 4}$, demonstrated a capacity to bind HER2 with an affinity of $50 \mathrm{nM}$ (16). The affinity maturation of $\mathrm{Z}_{\mathrm{HER} 2: 4}$ allowed selection of a new variant, $Z_{\text {HER2:342 }}$, which has an affinity of $22 \mathrm{pM}$ (17). The use of ${ }^{125}$ I-succinimidyl-para-iodobenzoate for indirect radioiodination of $\mathrm{Z}_{\mathrm{HER} 2: 342}$ made it feasible to create a labelled conjugate, ${ }^{125}$ I-PIB- $Z_{\text {HER2:342 }}$ which visualized HER2-expressing xenografts with high contrast (17). The small size of the Affibody ligand, $\sim 7 \mathrm{kDa}$, gave an excellent extravasation of peptides and a quick clearance from normal tissues. Indium-111 labelling of $\mathrm{Z}_{\mathrm{HER} 2: 342}$ using a benzylisothiocyanate derivative of DTPA was also successful, providing a conjugate suitable for imaging HER2 expression (18).

Radioactive isotopes of iodine have an appreciable potential for nuclear medicine, demonstrating a wide range of half-lives and emitted radiation. ${ }^{131} \mathrm{I}\left(\mathrm{T}_{1 / 2}=8 \mathrm{~d}, \mathrm{~B}^{-}\right)$is one of the most frequently used isotopes for targeting radionuclide therapy, which has proved efficacy in clinical trials $(19,20)$. ${ }^{123} \mathrm{I}\left[\mathrm{T}_{1 / 2}=13.3 \mathrm{~h}, 100 \%\right.$ electron capture (EC)] is widely used along with ${ }^{99 \mathrm{~m} T c}$ and ${ }^{111} \mathrm{In}$ for diagnostic purposes in $\gamma$ scintigraphy and SPECT (21). In the last few years, there has been a growing interest in the long-lived positron emitter ${ }^{124} \mathrm{I}$ $\left(\mathrm{T}_{1 / 2}=4.2 \mathrm{~d}, 23 \% \mathrm{~B}^{+}\right)$for labelling of macromolecules as positron emission tomography (PET) tracers $(13,22) .{ }^{125} \mathrm{I}$ $\left(\mathrm{T}_{1 / 2}=60 \mathrm{~d}, 100 \% \mathrm{EC}\right)$ is a convenient radionuclide for laboratory studies and is frequently used as a surrogate for ${ }^{123} \mathrm{I}$, ${ }^{124} \mathrm{I}$ and ${ }^{131} \mathrm{I}$ during the development stage. The attractiveness of radioiodine labelling of targeting proteins and peptides is based on the possibility to obtain a conjugate suitable for PET, SPECT or therapy by changing radionuclide. An ongoing common problem for radioiodine labels for internalizing peptides is the poor retention of radiocatabolites after intracellular degradation of targeting proteins by tumour cells (23). For this reason, the development of a residualizing radioiodine label, i.e. a label which remains trapped intracellularly after enzymatic degradation of targeting protein in lysosomes, is one of the major problems in radiochemistry. It is believed that the poor tumour retention of radiocatabolites after conventional labelling is caused by their ability to diffuse through cellular membranes due to high lipophilicity. Attachment of radioiodine to the targeting protein via a hydrophilic linker should improve the cellular retention of the radionuclide. Recently, we reported the use of closododecaborate derivative, [4-isothiocyanate-o-benzyl)-amino]undecahydro-closo-dodecaborate (DABI) as a linker for radiobromination (24) and radioiodination (25) of antitumour antibodies. The presence of closo-dodecaborate moiety should increase the overall hydrophilicity of the DABI. In vitro experiments on targeting HER2-expressing SKBR-3 cells with radiolabelled trastuzumab demonstrated that the use of DABI improves the retention by $55 \%$ in comparison with Chloramine-T direct label and by $42 \%$ in comparison with para-iodobenzoate indirect label (26). For this reason, we considered DABI as a potential linker for the attachment of radioiodine to the anti-HER2 Affibody molecule $\mathrm{Z}_{\mathrm{HER} 2: 342 \text {. }}$.

The goal of this study was to compare the biodistribution of the Affibody ligand $\mathrm{Z}_{\mathrm{HER} 2: 342}$ labelled with ${ }^{125} \mathrm{I}$ using DABI, designated as ${ }^{125} \mathrm{I}-\mathrm{DABI}-\mathrm{Z}_{\mathrm{HER} 2: 342}$ (Fig. 1A), with the biodistribution of ${ }^{125} \mathrm{I}-\mathrm{PIB}-\mathrm{Z}_{\text {HER2:342 }}$ (Fig. 1B), in order to select the best radioiodinated agent for imaging HER2 expression in malignant tumours. The use of analogues labelled ${ }^{123} \mathrm{I}$ for SPECT or ${ }^{124}$ I for PET was considered for future clinical applications. Our ultimate goal was to enable the imaging of HER2 expression in carcinomas to provide crucial information for deciding whether to use trastuzumab or another anti-HER2 molecular therapy on a given patient.

\section{Materials and methods}

Materials. Recombinant Affibody molecule $\mathrm{Z}_{\mathrm{HER} 2: 342}(17)$ was provided by Affibody AB (Bromma, Sweden). ${ }^{125}$ I was purchased from Amersham (Buckinghamshire, UK). Chloramine-T was from Sigma (St. Louis, MO, USA). Sodium metabisulfite was from Merck (Darmstadt, Germany). NAP-5 columns were purchased from Pharmacia (Uppsala, Sweden) and used according to the manufacturer's instructions. Methanol was purchased from Merck. Phosphate-buffered saline, PBS (10 mM, pH 7.4, $140 \mathrm{mM} \mathrm{NaCl}$ ), was prepared from $\mathrm{Na}_{2} \mathrm{HPO}_{4} \mathrm{x} 10 \mathrm{H}_{2} \mathrm{O}, \mathrm{NaH}_{2} \mathrm{PO}_{4} \times \mathrm{H}_{2} \mathrm{O}$ and $\mathrm{NaCl}$ (all of analytical grade or better; Merck). Borate buffer was prepared from $\mathrm{NaB}_{4} \mathrm{O}_{7} \times 10 \mathrm{H}_{2} \mathrm{O}$ (Sigma) and $\mathrm{HCl}$ (Merck). $\mathrm{N}$-succinimidyl-p-(tri-methylstannyl)benzoate was synthesized in our laboratory according to a protocol described previously (27). DABI was prepared in our laboratories as described by Sivaev and co-workers (28).

Radioactivity in all experiments was measured using an automated $\gamma$-counter (Wallac, Turku, Finland). The cells were counted on a cell counter from Beckman Coulter (Fullerton, CA, USA). Instant thin layer chromatography (ITLC) analysis was performed using ITLC SG plates, which were heated for $10 \mathrm{~min}$ at $125^{\circ} \mathrm{C}$ before analysis. A $70 \%$ solution of acetone in water was used as a mobile phase. Distribution of the radioactivity along the ITLC plates was measured on the 

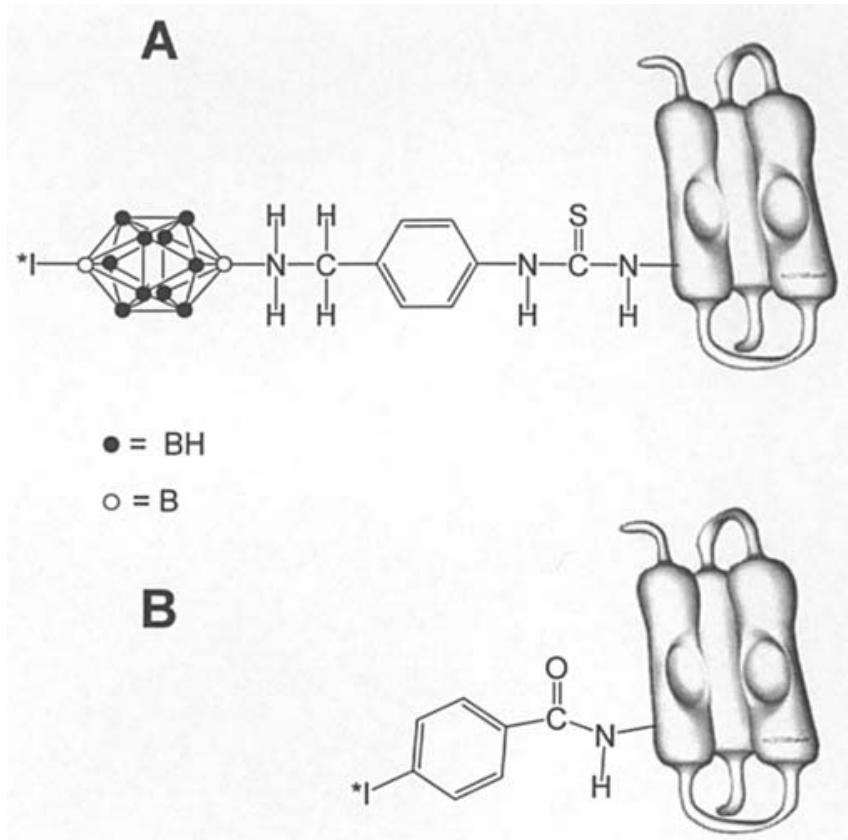

Figure 1. Chemical structures of linkers ${ }^{125}$ I-DABI (A) and ${ }^{125}$ I-PIB (B) attached to Affibody molecules. Structures of linkers are presented off-scale.

Cyclone $^{\mathrm{TM}}$ Storage Phosphor system and analyzed on the OptiQuant $^{\mathrm{TM}}$ Image analysis software.

Statistical analyses were performed using GraphPad Prism 4.0. In vitro experiments were carried out in triplicate.

Labelling with $N$-succinimidyl-para-(trimethylstannyl)benzoate, PIB. The Affibody molecule $\mathrm{Z}_{\mathrm{HER} 2: 342}$ was ${ }^{125} \mathrm{I}-$ labelled with N-succinimidyl-para-(trimethylstannyl)benzoate according to Orlova et al (17). Briefly, $10 \mu 1$ of $0.1 \%$ acetic acid solution in water and $5 \mu \mathrm{l} \mathrm{N}$-succinimidylpara-(trimethylstannyl)-benzoate solution $(1 \mathrm{mg} / \mathrm{ml}$ dissolved in $5 \%$ acetic acid in methanol) were mixed together in an Eppendorf tube $(1.5 \mathrm{ml})$ containing ${ }^{125} \mathrm{I}$-sodium iodide ( $38 \mathrm{MBq})$. Chloramine-T $(10 \mu \mathrm{l})(4 \mathrm{mg} / \mathrm{ml}$ in PBS) was added to initiate the labelling reaction. This mixture was slightly vortexed and incubated while shaking at room temperature for $5 \mathrm{~min}$. The reaction was stopped by the addition of $10 \mu 1$ sodium metabisulfite $(6 \mathrm{mg} / \mathrm{ml}$ in PBS). An Affibody ligand $\mathrm{Z}_{\mathrm{HER} 2: 342}(32.3 \mu 1,1.5 \mathrm{mg} / \mathrm{ml}$ solution in PBS) was added to the reaction mixture. Borate buffer $(60 \mu 1)$ was added to obtain a $\mathrm{pH}$ of 9.2 , and the reaction mixture was incubated by slight shaking at room temperature for $40 \mathrm{~min}$. The labelled compound ${ }^{125} \mathrm{I}-\mathrm{PIB}-\mathrm{Z}_{\mathrm{HER} 2: 342}$ conjugate, was then separated from non-reacted ${ }^{125} \mathrm{I}$ and other low-molecularweight reaction mixture components, using a NAP-5 column, pre-equilibrated with PBS. Radiochemical purity of the final solution was controlled using ITLC.

Labelling with DABI. A solution of $4 \mu \mathrm{l}$ of DABI $(1 \mathrm{mg} / \mathrm{ml}$ in water) was mixed with a stock solution of $10 \mu 1$ of ${ }^{125} \mathrm{I}-$ sodium iodide $(\sim 38 \mathrm{MBq})$ in an Eppendorf tube. Labelling was started by adding $10 \mu \mathrm{l}$ Chloramine- $\mathrm{T}(4 \mathrm{mg} / \mathrm{ml}$ in water) and stopped after $5 \mathrm{~min}$ of incubation by the addition of $10 \mu \mathrm{l}$ sodium metabisulfite $(4 \mathrm{mg} / \mathrm{ml}$ in water). An
Affibody ligand $\mathrm{Z}_{\mathrm{HER} 2: 342}(64 \mu \mathrm{l} ; 1.5 \mathrm{mg} / \mathrm{ml}$ solution in PBS) was added to the reaction mixture. Then $80 \mu 1$ of borate buffer was added to obtain a $\mathrm{pH}$ of 9.2 and the reaction mixture was incubated by slight shaking at room temperature for $60 \mathrm{~min}$. The separation of the labelled conjugate from non-reacted iodide and low-molecular-weight mixture components was performed by size-exclusion chromatography on a NAP-5 column, pre-equilibrated with PBS. The radiochemical purity of the final solution was controlled using ITLC.

Cell culture. The ovarian cancer cell line, SKOV-3, displaying $\sim 1-2 \times 10^{6}$ HER-2 receptors per cell (ATCC, American Type Culture Collection, VA, USA), was used in this study. The cells were maintained in Ham's F-10 Medium, supplemented with $10 \%$ fetal calf serum (Sigma, USA), 2 mM L-glutamine and PEST (penicillin $100 \mathrm{IU} / \mathrm{ml}$ and $100 \mu \mathrm{g} / \mathrm{ml}$ streptomycin) (all from Biochrom Kg., Germany). This medium is hereafter referred to as complete medium. The cells were cultured at $37^{\circ} \mathrm{C}$ in a humidified incubator with $5 \% \mathrm{CO}_{2}$ and trypsinized using trypsin-EDTA solution (0.25\% trypsin, $0.02 \%$ EDTA) from Biochrom $\mathrm{Kg}$.

In vitro cellular binding and retention studies. The HER2 binding specificity of the ${ }^{125} \mathrm{I}-\mathrm{PIB}-\mathrm{Z}_{\mathrm{HER} 2: 342}$ and ${ }^{125} \mathrm{I}-\mathrm{DABI}-$ $\mathrm{Z}_{\text {HER2:342 }}$ was examined by receptor saturation assay using living SKOV-3 cells. Cell monolayers were grown in Petri dishes (diameter $35 \mathrm{~mm}$ ) to a density of $\sim 0.4 \times 10^{6}$ cells $/$ dish. Before the experiment, the cells were rinsed once with $1 \mathrm{ml}$ complete medium. To determine the binding specificity, one set of three dishes was blocked using an excess (ratio 100:1, Affibody:receptor) of unlabelled Affibody molecules (890 ng in $0.5 \mathrm{ml}$ medium per dish). To the other set (3 dishes were used for each conjugate) $0.5 \mathrm{ml}$ of complete medium was added. Then $0.5 \mathrm{ml}$ medium with labelled conjugate (the amount of conjugate corresponds to a ratio of $1: 1$ receptor to protein) was added to both series of dishes. After $2 \mathrm{~h}$ of incubation at $37^{\circ} \mathrm{C}$ the incubation media were collected. The cells were washed 6 times with cold, serum-free medium and trypsinized with $0.5 \mathrm{ml}$ trypsin-EDTA for $10 \mathrm{~min}$ at $37^{\circ} \mathrm{C}$. Another $0.5 \mathrm{ml}$ of medium was added to the cells, and they were collected after re-suspension. The radioactivity of both the incubation medium and the cell suspension was measured in the $\gamma$-counter.

For the evaluation of cellular retention, the cells were seeded in Petri dishes (diameter $35 \mathrm{~mm}$ ), $\sim 0.4 \times 10^{5}$ cells/dish. The cell monolayers were washed once with complete medium and then pre-incubated with $1 \mathrm{ml}$ of different ${ }^{125}$ I-labelled Affibody molecule ( ${ }^{125} \mathrm{I}-\mathrm{PIB}-\mathrm{Z}_{\mathrm{HER} 2: 342}$ or ${ }^{125} \mathrm{I}-$ DABI-Z $Z_{\text {HER2:342 }}$ ) solutions (calculated ratio of one Affibody molecule per receptor) for $2 \mathrm{~h}$ at $37^{\circ} \mathrm{C}$. The incubation was interrupted by washing the cells 6 times with cold, serumfree culture medium and incubated again with $1 \mathrm{ml}$ complete medium for $0-24 \mathrm{~h}$ at $37^{\circ} \mathrm{C}$ in $5 \% \mathrm{CO}_{2}$. The cells were harvested at $0.5,1,2,4,8$ and $24 \mathrm{~h}$ and the incubation medium was collected for radioactivity counting. The cells were washed again 6 times with cold, serum-free medium and treated with $0.5 \mathrm{ml}$ trypsin-EDTA for $10 \mathrm{~min}$ at $37^{\circ} \mathrm{C}$. Another $0.5 \mathrm{ml}$ of medium was added and the cell suspension was collected. The radioactivity of the collected fractions was measured on a $\gamma$-counter. 


\section{Retention of radioactivity in SKOV3 cells}

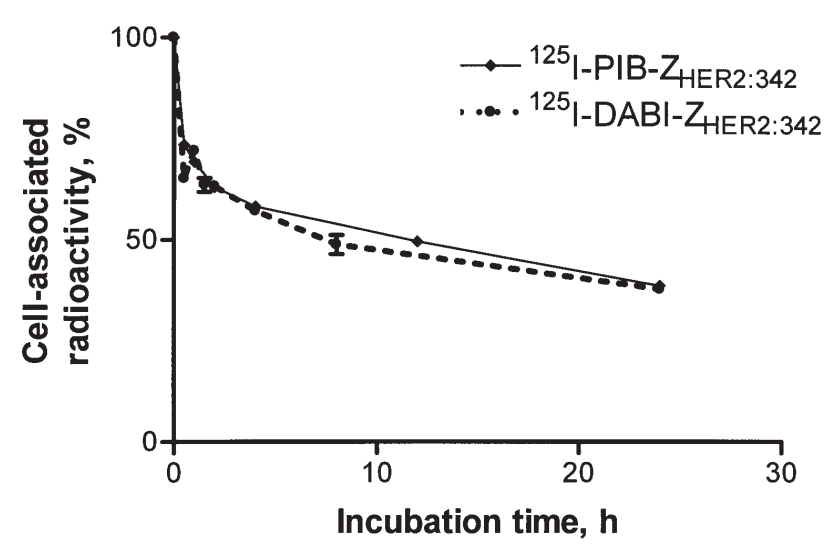

Figure 2. Cell-associated ${ }^{125}$ I-radioactivity as a function of time after the interrupted incubation of SKOV-3 cells with ${ }^{125} \mathrm{I}-\mathrm{PIB}-\mathrm{Z}_{\mathrm{HER} 2: 342}$ and ${ }^{125} \mathrm{I}-$

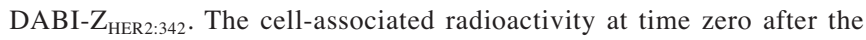
interrupted incubation was considered as $100 \%$. Data are presented as mean $\pm \mathrm{SD}(\mathrm{n}=3)$. Error bars may not be seen because they are smaller than the point symbols.

Biodistribution of radiolabelled conjugates in tumour xenograft-bearing mice. The animal study was approved by the local Ethics Committee for Animal Research. Female outbreed BALB/c nu/nu mice (10-12 weeks old at arrival) were acclimatized for 1 week at the Rudbeck Laboratory animal facility before a subcutaneous (s.c.) injection of $\sim 5 \times 10^{6} \mathrm{SKOV}-3$ cells in the left hind leg. The xenografts were allowed to become established for 2 months.

Groups of four (time point $24 \mathrm{~h}$ ) or eight animals (time point $4 \mathrm{~h}$ ) were used for the biodistribution study. All mice were injected subcutaneously with $\sim 50 \mu 1(\sim 100 \mathrm{kBq}$, overall peptide dose of about $1 \mu \mathrm{g}$ ) of radiolabelled Affibody solution ( ${ }^{125} \mathrm{I}_{-\mathrm{PIB}} \mathrm{Z}_{\mathrm{HER} 2: 342}$ or ${ }^{125} \mathrm{I}-\mathrm{DABI}-\mathrm{Z}_{\mathrm{HER} 2: 342}$ ) in PBS. After 4 or $24 \mathrm{~h}$, the mice were anesthetized by a lethal dose of Rompun/Ketalar (Ketalar, $10 \mathrm{mg} / \mathrm{ml}$, Rompun, $1 \mathrm{mg} / \mathrm{ml}$; $20 \mu \mathrm{l}$ of solution per gram of body weight) and sacrificed by heart puncture. Blood was collected using heparinized syringes (heparin $5000 \mathrm{IE} / \mathrm{ml}$, from Leo Pharma, Copenhagen, Denmark). Organ and tissue samples (blood, heart, lung, liver, spleen, pancreas, kidney, stomach, colon, salivary gland, muscle, thyroid, bone, the entire intestinal tract with its content) and tumours were excised and weighed, and their radioactivity content was measured. A small portion of intestine was emptied of its contents, and its radioactivity was measured as well. The radioactivity accumulation in different organs and tissues was expressed as percent of injected radioactivity per gram $(\% \mathrm{IA} / \mathrm{g})$.

$\gamma$-Camera imaging. SKOV-3 xenografts were established for $\sim 2$ months, as described above. The tumours had a diameter of about $0.5 \mathrm{~cm}^{3}$ on the day of the experiment. Each mouse was injected with $90 \mu \mathrm{l}(3 \mu \mathrm{g}, 3 \mathrm{MBq}){ }^{125} \mathrm{I}-\mathrm{PIB}-\mathrm{Z}_{\mathrm{HER} 2: 342}$ or ${ }^{125} \mathrm{I}-\mathrm{DABI}-\mathrm{Z}_{\mathrm{HER} 2: 342}$ solution in PBS. After $6 \mathrm{~h}$, the mice were sacrificed with a lethal dose of Ketalar/Rompun followed by cervical dislocation. The mice were imaged immediately after euthanasia using an e.CAM (Siemens, Erlangen,
Germany) $\gamma$-camera with a low-energy high-resolution collimator.

\section{Results}

Labelling. The use of indirect radioiodination provided an isolated yield between 42 and $55 \%$ for ${ }^{125} \mathrm{I}-\mathrm{PIB}-\mathrm{Z}_{\mathrm{HER} 2: 342}$ and between 60 and $63 \%$ for ${ }^{125} \mathrm{I}-\mathrm{DABI}-\mathrm{Z}_{\mathrm{HER} 2: 342}$. This corresponds to an average attachment of $0.84-1.1{ }^{125}$ I-PIB or 1.2-1.25 ${ }^{125} \mathrm{I}-\mathrm{DABI}$ prosthetic group per Affibody molecule. We intentionally avoided a higher degree of modification, since the binding site of Affibody molecules contains one lysine. A large number of prosthetic groups increases the probability of modification of this lysine and deactivation of the conjugate. Purification of conjugates using disposable NAP-5 sizeexclusion columns provided radiochemical purity $>96 \%$ in all labelling.

In vitro cellular binding and retention studies. We reported previously (17) that the use of PIB as a linker for the attachment of radioiodine to $\mathrm{Z}_{\mathrm{HER} 2: 342}$ Affibody ligand preserves the binding capacity of the molecule. The present study confirmed this since a high degree of binding blocking was demonstrated in the cell specificity test. This study demonstrated that an attachment of 1.2-1.24 DABI linker per $\mathrm{Z}_{\text {HER2:342 }}$ Affibody provided a radiolabelled conjugate with a preserved binding specificity. The receptor saturation demonstrated that the binding was reduced from $9.41 \pm 0.38 \%$ to $0.25 \pm 0.062 \%$ of added radioactivity.

The results of the cellular retention experiments are presented in Fig. 2. It was found that both labels had the same retention pattern, where a relatively quick decrease of cell-associated radioactivity, probably caused by dissociation of the membrane-bound conjugate, was followed by a relatively slow decrease. The latter process was most likely caused by intracellular degradation of conjugates with subsequent excretion of degradation products. There was no appreciable difference in cell-associated radioactivity at any moment after the interrupted incubation.

A better distinction between membrane-bound and internalized radioactivity would be helpful for the interpretation of the results of the cell studies. We attempted to determine the internalized fraction by acid wash, similar to a method previously applied to EGF-based conjugates (29). However, validation experiments demonstrated that this method could not remove the radioactivity completely from the cell surface after incubation on ice, probably due to the very strong binding of radioiodinated $\mathrm{Z}_{\text {HER2:342 }}$ to HER2 (data not shown). The same effect was observed with the Affibody molecule $\mathrm{Z}_{\text {HER2:342 }}$ labelled with ${ }^{111}$ In using benzyl-DTPA (18). Several experiments were also performed using alkaline buffers, but subsequent efforts to remove the radioactivity that was bound during incubation on ice without destroying the cellular membranes were unsuccessful. This meant that all tested methods would overestimate the internalized radioactivity. For this reason, a detailed internalization assay was not performed.

Biodistribution of radiolabelled conjugates in tumour xenograft-bearing mice. Data concerning the biodistribution 

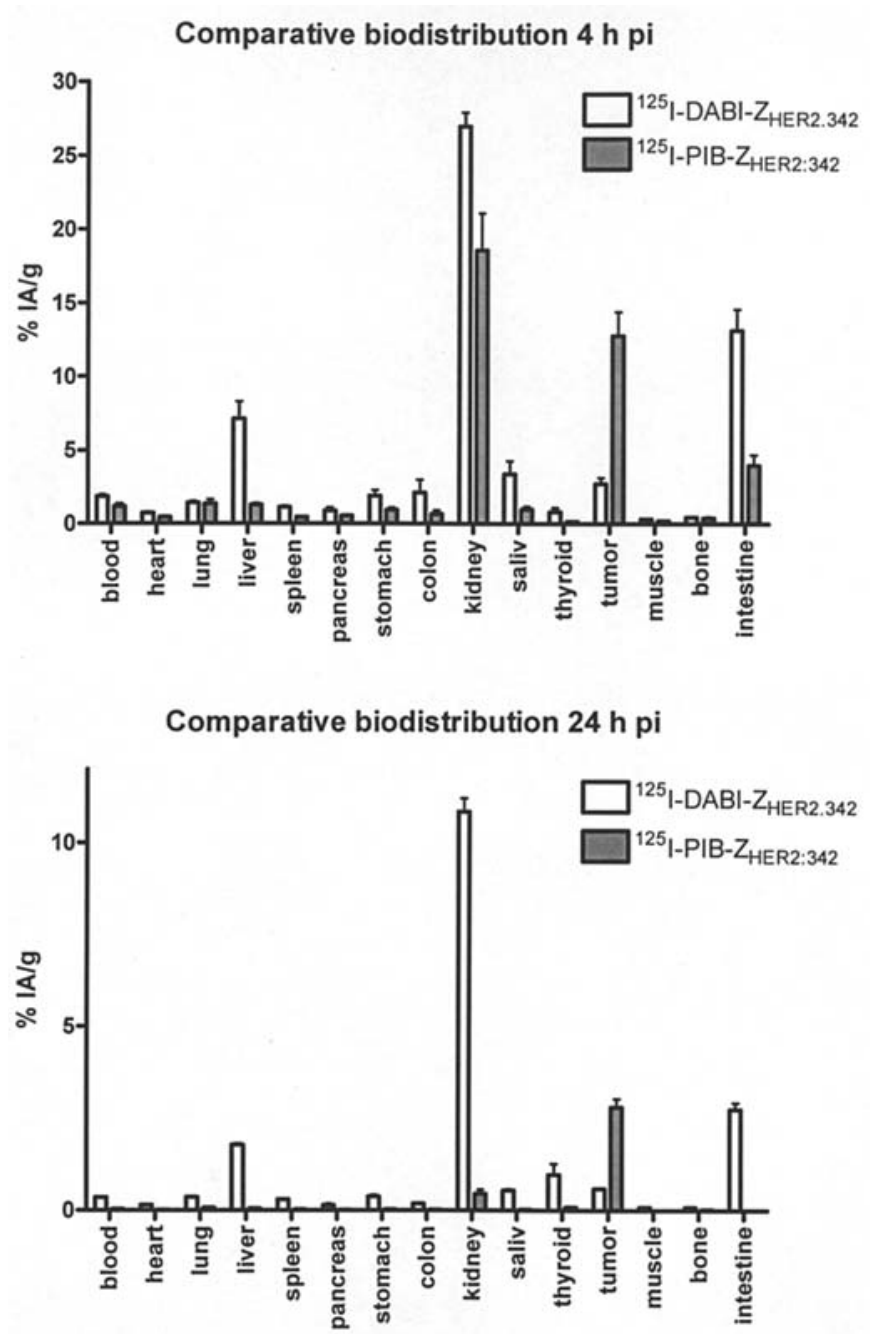

Figure 3. Comparative biodistribution of ${ }^{125} \mathrm{I}-\mathrm{PIB}-\mathrm{Z}_{\mathrm{HER} 2 \cdot 342}$ and ${ }^{125} \mathrm{I}$-DABI$\mathrm{Z}_{\mathrm{HER2} 2: 342}$ in Balb/c nude mice bearing SKOV-3 xenografts at $4 \mathrm{~h}$ pi (upper panel) and $24 \mathrm{~h}$ pi (lower panel). Data are presented as the mean \pm SD for eight (4 h pi) or four ( $24 \mathrm{~h} \mathrm{pi)} \mathrm{animals.}$

of ${ }^{125}{ }^{I}-\mathrm{PIB}-\mathrm{Z}_{\mathrm{HER} 2: 342}$ and ${ }^{125} \mathrm{I}-\mathrm{DABI}-\mathrm{Z}_{\mathrm{HER} 2: 342}$ are presented in Fig. 3. Data concerning the biodistribution of ${ }^{125} \mathrm{I}-\mathrm{PIB}-$ $\mathrm{Z}_{\mathrm{HER} 2: 342}$ were in agreement with the data published by Orlova et al (17). The biodistribution of this compound was characterized by rather quick blood clearance and washout from all organs and tissues. Already at $4 \mathrm{~h}$ pi, the radioactivity concentration in the tumour was higher than that in all the organs and tissues except the kidneys. The relatively high uptake in this organ is caused predominantly by the renal excretion pathway. The level of hepatobiliary excretion was low, which was manifested by low radioactivity content in the liver, colon and the intestinal tract with its contents. However, there was an appreciable clearance of radioactivity from the tumour at $24 \mathrm{~h}$ pi. The rate was slower than the rate of clearance from other organs, which made it possible to obtain a tumour-to-kidney ratio of more than six times at this point.

The biodistribution of ${ }^{125} \mathrm{I}-\mathrm{DABI}-\mathrm{Z}_{\mathrm{HER} 2: 342}$ differed appreciably from the biodistribution of ${ }^{125} \mathrm{I}-\mathrm{PIB}-\mathrm{Z}_{\mathrm{HER} 2: 342}$. Two aspects were dominating. First the blood clearance of ${ }^{125} \mathrm{I}-$

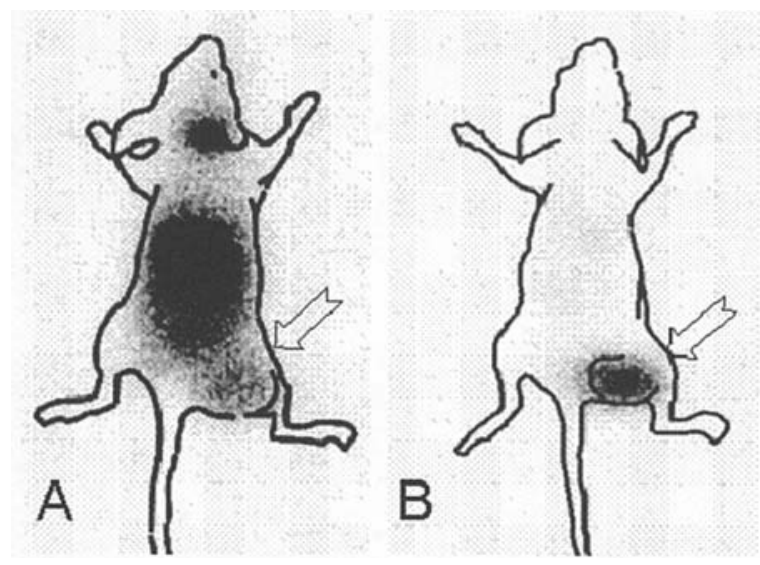

Figure 4. Imaging of HER2 expression in SKOV-3 xenografts in Balb/c nude mice using ${ }^{125} \mathrm{I}-\mathrm{DABI}-\mathrm{Z}_{\mathrm{HER} 2: 342}(\mathrm{~A})$ and ${ }^{125} \mathrm{I}-\mathrm{PIB}-\mathrm{Z}_{\mathrm{HER} 2: 342}(\mathrm{~B})$. Planar $\gamma$-camera images were collected $6 \mathrm{~h}$ after administration of radiolabelled tracers. Tumours (arrows) were clearly visualized. Animal contours, which were derived from digital photographs, were superimposed over $\gamma$-camera images to facilitate interpretation.

DABI-Z $Z_{\text {HER2:342 }}$ was apparently slower, and at $4 \mathrm{~h}$ pi the blood level of this compound was 1.5 times higher than the level of

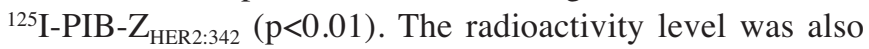
significantly higher $(\mathrm{p}<0.05)$ in the heart, liver, spleen, stomach, kidney, thyroid and muscle. A second important factor was a change in the excretion pathway. Renal excretion remained to be important for ${ }^{125} \mathrm{I}-\mathrm{DABI}-\mathrm{Z}_{\mathrm{HER} 2: 342}$, since the radioactivity accumulation in the kidney was even higher than in the case of ${ }^{125}{ }^{I}-\mathrm{PIB}-\mathrm{Z}_{\text {HER2:342 }}$. However, the hepatobiliary excretion pathway also played an appreciable role, as seen by an increased radioactivity in the liver and gastrointestinal tract. The accumulation of radioactivity in the tumour was reduced 4.7 times in comparison with ${ }^{125} \mathrm{I}-$

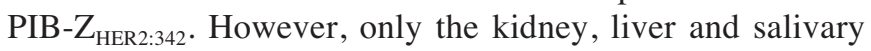
gland accumulated more radioactivity per gram than the tumour.

A comparison of the biodistribution at $4 \mathrm{~h}$ and $24 \mathrm{~h}$ pi showed no difference between clearance rates from the tumours between ${ }^{125} \mathrm{I}-\mathrm{DABI}-\mathrm{Z}_{\mathrm{HER} 2: 342}$ and ${ }^{125} \mathrm{I}-\mathrm{PIB}-\mathrm{Z}_{\mathrm{HER} 2: 342}$. Tumour uptake was reduced 4.60- and 4.55-fold, respectively. The residualizing properties of ${ }^{125}$ I-DABI-label were demonstrated, unfortunately, mainly in a higher retention of radioactivity in the kidney and liver.

$\gamma$-Camera imaging. The difference in biodistribution was clearly visualized by $\gamma$-camera at $6 \mathrm{~h}$ pi (Fig. 4). In the case of ${ }^{125}$ I-PIB-Z $Z_{\text {HER 2:342 }}$, the tumour xenograft was the only prominent site of accumulation. At that time, even the radioactivity in the kidney was lower than that in the tumour. For this reason, the tumour was clearly and unambiguously visualized. The use of ${ }^{125} \mathrm{I}-\mathrm{DABI}-\mathrm{Z}_{\mathrm{HER} 2: 342}$ enabled visualization of HER2 expression as well. However, a combination of efficient retention of radioactivity in the excretory organs (kidney and liver) and hepatobiliary excretion determined a high intensity signal (higher than from the tumour) from the abdominal area. The radioactivity accumulation in the salivary gland was also visualized. 
Table I. Comparison of tumour-to-organ ratios for different HER2-targeting proteins.

\begin{tabular}{|c|c|c|c|c|c|c|}
\hline & $\begin{array}{l}{ }^{125} \mathrm{I}-\mathrm{PIB}-\mathrm{Z}_{\mathrm{HER} 2: 342} \\
\text { (present study) }\end{array}$ & $\begin{array}{c}{ }^{125} \mathrm{I}-\mathrm{DABI}-\mathrm{Z}_{\mathrm{HER} 2: 342} \\
\text { (present study) }\end{array}$ & $\begin{array}{c}741 \mathrm{~F} 8-2 \mathrm{sFv} \\
(46)^{\mathrm{a}}\end{array}$ & $\begin{array}{c}741 \mathrm{~F} 8-2\left(\mathrm{sFv}^{\prime}\right) 2 \\
(47)^{\mathrm{a}}\end{array}$ & $\begin{array}{c}10 \mathrm{H} 8 \\
\text { hinge-minibody } \\
(14)^{\mathrm{a}}\end{array}$ & $\begin{array}{c}\text { C6.5 scFv } \\
\text { diabody } \\
(48)^{\mathrm{a}}\end{array}$ \\
\hline Blood & 10.7 & 1.50 & 2.6 & 1.3 & 0.16 & 1.5 \\
\hline Kidney & 0.7 & 0.10 & 1.4 & 1.5 & 0.43 & 1.9 \\
\hline Liver & 9.9 & 0.40 & 2.8 & 2.4 & 0.80 & 3.6 \\
\hline Lung & 9.4 & 1.90 & 2.1 & 1.4 & 0.52 & 1.4 \\
\hline Muscle & 60.0 & 8.90 & 6.0 & 7.5 & & 7.1 \\
\hline Spleen & 28.2 & 2.40 & 2.0 & 1.9 & 1.10 & 3.2 \\
\hline Stomach & 13.1 & 1.43 & 0.7 & 0.6 & & 1.4 \\
\hline
\end{tabular}

Data for ${ }^{125}$ I-PIB-Z $Z_{\text {HER2:342 }}$ and ${ }^{125} \mathrm{I}-\mathrm{DABI}-\mathrm{Z}_{\mathrm{HER} 2: 342}$ are found in this study. aData for other targeting proteins were taken directly from referred publications or calculated on the basis of data published therein.

\section{Discussion}

One feature of a post-genomic era would most likely be the further development of personalized medicine, i.e. the use of a treatment which is the most effective for a given patient. The need to determine ER/PR (estrogen receptor/ progesterone receptor) and HER2 receptor expression in each newly diagnosed breast cancer patient $(6,7)$ in order to select the most suitable therapy is a good example of such an approach in clinical practice. A prerequisite for the clinical implementation of personalised molecular medicine is, however, a highly accurate detection of the molecular signature of the disease. The current common practice of biopsy with subsequent analysis using immunohistochemistry or FISH is helpful, but false-negative results cannot be completely excluded. This can be exemplified by a negative determination of HER 2 expression in primary tumours available after surgery, e.g. in the case of breast cancer, where $14 \%$ of the metastases actually express HER2 (30). In this case, HER2-expressing metastases would evade therapy, since such patients would be considered as noneligible for HER2-targeting therapy. Radionuclide imaging of HER 2 expression in both the primary tumour and metastases would solve this problem.

The introduction of radionuclide imaging into routine clinical practice is highly dependent on the sensitivity of detection. For high sensitivity, a high contrast, i.e. high tumour-to-normal organ ratio, is crucial. High contrast is obtained by high-affinity binding of the molecular target by the targeting agent, efficient clearance of radioactivity from healthy tissues, and good retention of radioactivity in the tumour until radioactivity is cleared from healthy tissues (31). The use of a low-molecular-weight high-affinity tracer, such as the radioiodinated Affibody ligand $\mathrm{Z}_{\text {HER2:342 }}$, provides excellent targeting and efficient blood clearance (17). Still, the contrast of tumour imaging using radioiodinated $\mathrm{Z}_{\mathrm{HER} 2: 342}$ might be further increased if the radioiodine label is residualizing, i.e. would be trapped inside the tumour cell after internalization and lysosomal degradation of targeting protein. Our experience with the targeting of epidermal growth factor receptors (EGFR) using the radioiodinated epidermal growth factor (EGF) (32) demonstrated that ${ }^{125} \mathrm{I}-$ succinimidyl-para-iodobenzoate, which was used in our previous studies for radioiodination of Affibody molecules, is non-residualizing. We reasoned that the development of a residualizing radioiodine label for $\mathrm{Z}_{\text {HER2:342 }}$ would further improve imaging contrast.

Free diffusion of radiocatabolites from cancer cells is facilitated by their lipophilicity $(23,33)$. For this reason, development of linkers for radioiodine, which are charged and hydrophilic, is considered as a suitable strategy to develop residualizing radioiodine labels. Different moieties, which are charged at lysosomal $\mathrm{pH}$, have been evaluated, including derivatives of pyridine (34), guanidine (35), Dlysine containing peptide sequences (36), phosphonates (37), and tyrosine-containing derivatives of DTPA $(38,39)$. The use of polyhedral boron anions (PBA) as negatively charged linkers is a focus of our group (40) as well as other researchers $(41,42)$. The closo-dodecaborate dianion provides a molecular moiety that can be easily radioiodinated, and confers a negative charge to a linker, which increases its hydrophilicity. The incorporation of benzyl-isothiocyanate enables the coupling of closo-dodecaborate to amino groups on the N-terminal or lysines of a protein. In this study, we radioiodinated the Affibody ligand $\mathrm{Z}_{\mathrm{HER} 2: 342}$ using DABI with a yield exceeding that of indirect radioiodination using PIB. Both conjugates ( ${ }^{125} \mathrm{I}-\mathrm{DABI}-\mathrm{Z}_{\mathrm{HER} 2: 342}$ and ${ }^{125} \mathrm{I}-\mathrm{PIB}-\mathrm{Z}_{\mathrm{HER} 2: 342}$ ) retained the capacity to specifically bind HER2-expressing cells.

In a previous study, we compared the cellular retention of radioiodine, which was delivered to HER2-expressing cancer cells by anti-HER2 antibody trastuzumab which was labelled directly using Chloramine-T and indirectly using PIB and DABI (26). The use of DABI improved retention in comparison with the use of both Chloramine-T and PIB. However, there was no difference in cellular retention when PIB and DABI were used in this study for radioiodination of the Affibody ligand $\mathrm{Z}_{\mathrm{HER} 2: 342}$. It should be noted that cellular retention of a label depends both on the chemical nature of the linker molecule and on the biological nature of the 
targeting molecule. The binding of trastuzumab and the binding of Affibody ligand can cause a different internalization pathway with different intracellular compartmentalisation. We have noticed that the binding of $\mathrm{Z}_{\mathrm{HER} 2: 342}$ Affibody ligands to receptors is unusually strong, and bound $\mathrm{Z}_{\mathrm{HER} 2: 342}$ does not dissociate from the receptors at a low $\mathrm{pH}$ during acid wash. As a result, the Affibody might not dissociate from receptors in an endosomal compartment with subsequent transport to a lysosomal compartment for degradation, but recycle with the HER2 receptor back to the cell surface. In this situation, an advantage of a residualizing linker is minimized. On the other hand, the disadvantage of a non-residualizing linker would be also less pronounced. A comparison with our previous data shows that the cellular retention of $\mathrm{Z}_{\mathrm{HER} 2: 342}$ was apparently much better than the retention of EGF of similar size (32), when the same paraiodobenzoate linker was used for radioiodination. The residualizing properties of DABI were pronounced in this study in the excretory organs, particularly in the kidneys. The re-absorption of peptides in the proximal tubulae, presumably by megalin (43), prevents loss of amino acids from the body. Apparently, recycling should not play a substantial role in this process. For this reason, the residualizing properties of the label should be more clearly seen in this case. Indeed, the radioactivity concentration in the kidneys was decreased only 2.5 -fold between $4 \mathrm{~h}$ and $24 \mathrm{~h}$ pi in the case of closo-dodecaborate-containing linker, while the decrease for para-iodobenzoate was 40 -fold, presumably due to leakage of radiocatabolites into the blood with subsequent quick excretion into the urine. A similar effect was observed in the liver, where the decrease of radioactivity between 4 and $24 \mathrm{~h}$ pi was only 4-fold for DABI and 30-fold for paraiodobenzoate. It should be noted that the residualizing properties of DABI seem to be modest in comparison with the properties of such well-recognised residualizing labels as radiometal chelates. For example, the radioactive concentration of an ${ }^{111} \mathrm{In}$-benzyl-DTPA label attached to a $\mathrm{Z}_{\mathrm{HER} 2: 342}$ Affibody molecule decreased only 1.3-fold both in the kidney and in the liver between 4 and $24 \mathrm{~h}$ pi (18).

The uptake of ${ }^{125}$ I-DABI-Z $Z_{\text {HER2:342 }}$ in the liver deserves a separate discussion, because it had the most apparent negative impact on tumour targeting. The liver is a common metastatic site for many carcinomas, and high radioactivity uptake in this organ diminishes the diagnostic value of an imaging agent. Most likely, this effect is associated with the use of closo-dodecaborate, since neither the use of paraiodobenzoate nor ${ }^{111}$ In-benzyl-DTPA (18) for labelling of the $\mathrm{Z}_{\text {HER2:342 }}$ Affibody molecule caused a high hepatic uptake. This effect was quite unexpected, since earlier studies on radioiodinated monoclonal antibodies (44) did not indicate such influence. Though the use of DABI caused an elevated uptake of radioactivity in the liver and spleen at $1.5 \mathrm{~h}$ pi in comparison with para-iodobenzoate and Chloramine-T labels, there was no significant difference between the labels at $6 \mathrm{~h}$ pi. In another study (45), a biodistribution of radioiodinated closo-dodecaborate was investigated in rats. No elevated uptake of radioactivity in the liver and spleen was detected, and closo-dodecaborate was very quickly cleared from the blood. Liver uptake of closo-dodecaborate may be associated with its attachment to protein and, as a consequence, with its prolonged time in the blood circulation. On the other hand, short peptides with a high degree of modification are taken up by the liver more avidly than the bulky IgG, where the attachment of 1-3 groups modifies the molecule to a much lesser extent. The absorption of the targeting conjugate by the liver results in less molecules remaining available for targeting, which causes a diminished tumour uptake of ${ }^{125} \mathrm{I}-\mathrm{DABI}-\mathrm{Z}_{\mathrm{HER} 2: 342}$ in comparison with ${ }^{125} \mathrm{I}-$

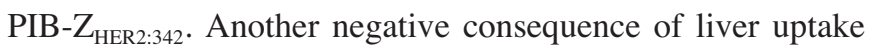
is the excretion of radioactivity (as intact protein or its radiocatabolites) via bile into the intestines. As a result, the appearance of radioactivity in the abdomen obscures extrahepatic abdominal metastases.

$\gamma$-Camera imaging confirmed the clear advantage of paraiodobenzoate in comparison with DABI. Although the tumour was visualized using ${ }^{125} \mathrm{I}_{-} \mathrm{DABI}-\mathrm{Z}_{\mathrm{HER} 2: 342}$ at $6 \mathrm{~h}$ pi, high radioactivity retention in the kidney, liver and intestines was an obstacle for imaging tumours and metastases located in the peritoneum. At the same time, even a modest retention of ${ }^{125}$ I-PIB- $Z_{\text {HER2:342 }}$ in tumours in combination with a quick radioactivity washout from normal organs enabled a high contrast tumour imaging. Note that at this moment radioactivity in the tumour appreciably exceeded the radioactivity in the kidneys.

Due to the high diagnostic importance of HER2 detection, a number of targeting agents against HER2 were developed. It was of interest to compare radioiodinated Affibody ligands with other radioiodinated anti-HER2 conjugates. Such a comparison at $4 \mathrm{~h}$ pi is presented in Table I. We intentionally limited ourselves to agents with low molecular weight, which potentially enabled imaging shortly after injection. The majority of studies have been performed using SKOV-3 ovarian carcinoma xenografts, as in the current study. The only exception was a study by Olafsen and co-workers (14), which was performed on mice bearing MCF-7 xenografts. Apparently, the use of such a historical control is associated with pitfalls, since the animals, sampling technique and measurement equipment are different. However, such a comparison enables judgement about the relative merits of conjugates. The tumour-to-organ ratio of the ${ }^{125}$ I-DABI$\mathrm{Z}_{\mathrm{HER} 2: 342}$ Affibody conjugate was found to be in the same range as other constructs in the presented studies (Table I) in most of the organs except in the liver and kidneys, where we found a higher uptake. However, it is apparent that ${ }^{125} \mathrm{I}$-PIB$\mathrm{Z}_{\text {HER2:342 }}$ provides an apparently better tumour-to-organ ratio at this point, not only in comparison with ${ }^{125} \mathrm{I}-\mathrm{DABI}-\mathrm{Z}_{\mathrm{HER} 2: 342}$, but also in comparison with other HER2-imaging tracers reported in the literature. A more detailed analysis of the literature data indicates that the better contrast provided by ${ }^{125} \mathrm{I}-\mathrm{PIB}-\mathrm{Z}_{\text {HER2:342 }}$ is mainly due to fast blood clearance of radioactivity for non-specific compartments and blood.

In conclusion, the HER2-targeting Affibody molecule $\mathrm{Z}_{\mathrm{HER} 2: 342}$ was successfully radioiodinated using a DABI linker. The ${ }^{125} \mathrm{I}-\mathrm{DABI}-\mathrm{Z}_{\mathrm{HER} 2: 342}$ preserved the capacity to specifically bind HER2-expressing cells. However, the label provided no advantage in cellular retention and caused an unfavourably high liver uptake. For this reason, ${ }^{125}$ I-PIB$\mathrm{Z}_{\mathrm{HER} 2: 342}$ is a superior radioiodinated conjugate for the imaging of HER2 expression in vivo. 


\section{Acknowledgements}

The authors thank Mrs. Kristina Lundquist for a linguistic check of the manuscript and Mrs. Veronika Asplund Eriksson for keeping the cell laboratory in excellent working condition. Financial support was provided by the Swedish Cancer Society (Cancerfonden).

\section{References}

1. Natali PG, Nicotra MR, Bigotti A, Venturo I, Slamon DJ, Fendly BM and Ullrich A: Expression of the p185 encoded by HER2 oncogene in normal and transformed human tissues. Int $\mathbf{J}$ Cancer 45: 457-461, 1990.

2. Press MF, Cordon-Cardo C and Slamon DJ: Expression of the HER-2/neu proto-oncogene in normal human adult and fetal tissues. Oncogene 5: 953-962, 1990.

3. Yarden Y and Sliwkowski MX: Untangling the ErbB signalling network. Nat Rev Mol Cell Biol 2: 127-137, 2001.

4. Carter P, Presta L, Gorman CM, Ridway JB, Henner D, Wong WL, Rowland AM, Kotts C, Carver ME and Shepard HM: Humanization of an anti-p185HER2 antibody for human cancer therapy. Proc Natl Acad Sci USA 89: 4285-4289, 1992.

5. Ocana A, Rodriguez CA and Cruz JJ: Integrating trastuzumab in the treatment of breast cancer. Current status and future trends. Clin Transl Oncol 7: 99-100, 2005.

6. Bast RC Jr, Ravdin P, Hayes DF, Bates S, Fritsche H Jr, Jessup JM, Kemeny N, Locker GY, Mennel RG and Somerfield MR; American Society of Clinical Oncology Tumor Markers Expert Panel: 2000 update of recommendations for the use of tumor markers in breast and colorectal cancer: clinical practice guidelines of the American Society of Clinical Oncology. J Clin Oncol 19: 1865-1878, 2001

7. Molina R, Barak V, van Dalen A, Duffy MJ, Einarsson R, Gion M, Goike H, Lamerz R, Nap M, Soletormos G and Stieber P: Tumor markers in breast cancer - European Group on tumor marker recommendations. Tumour Biol 26: 281-293, 2005.

8. Heppeler A, Froidevaux S, Eberle AN and Maecke HR: Receptor targeting for tumor localisation and therapy with radiopeptides. Curr Med Chem 7: 971-994, 2000.

9. Klapper LN, Glathe S, Vaisman N, Hynes NE, Andrews GC, Sela M and Yarden Y: The ErbB-2/HER2 oncoprotein of human carcinomas may function solely as a shared coreceptor for multiple stroma-derived growth factors. Proc Natl Acad Sci USA 96: 4995-5000, 1999.

10. Behr TM, Behe M and Wormann B: Trastuzumab and breast cancer. N Engl J Med 345: 995-996, 2001.

11. Smith-Jones PM, Solit DB, Akhurst T, Afroze F, Rosen N and Larson SM: Imaging the pharmacodynamics of HER2 degradation in response to Hsp90 inhibitors. Nat Biotechnol 22: 701-706, 2004.

12. Tang Y, Wang J, Scollard DA, Mondal H, Holloway C, Kahn HJ and Reilly RM: Imaging of HER2/neu-positive BT-474 human breast cancer xenografts in athymic mice using ${ }^{111} \mathrm{In}$-trastuzumab (Herceptin) Fab fragments. Nucl Med Biol 32: 51-58, 2005.

13. Gonzalez Trotter DE, Manjeshwar RM, Doss M, Shaller C, Robinson MK, Tandon R, Adams GP and Adler LP: Quantitation of small-animal (124)I activity distributions using a clinical PET/CT scanner. J Nucl Med 45: 1237-1244, 2004.

14. Olafsen T, Tan GJ, Cheung CW, Yazaki PJ, Park JM, Shively JE, Williams LE, Raubitschek AA, Press MF and Wu AM: Characterization of engineered anti-p185HER-2 (scFv-CH3)2 antibody fragments (minibodies) for tumor targeting. Protein Eng Des Sel 17: 315-323, 2004

15. Nord K, Gunneriusson E, Ringdahl J, Ståhl S, Uhlén M, and Nygren P-Å: Binding proteins selected from combinatorial libraries of an alpha-helical bacterial receptor domain. Nat Biotechnol 15: 772-777, 1997.

16. Wikman M, Steffen A-C, Gunneriusson E, Tolmachev V, Adams GP, Carlsson J and Ståhl S: Selection and characterisation of HER2/neu-binding affibody ligands. Protein Eng Des Sel 17: 455-462, 2004.

17. Orlova A, Magnusson M, Eriksson T, Nilsson M, Larsson B, Höiden-Guthenberg I, Widström C, Carlsson J, Tolmachev V, Ståhl S and Nilsson F: Tumor imaging using a picomolar affinity HER 2 binding Affibody molecule. Cancer Res 66: 4339-4348, 2006.
18. Tolmachev V, Nilsson FY, Widström C, Andersson K, Gedda L, Wennborg A and Orlova A: ${ }^{111}$ In-benzyl-DTPA-Z ${ }_{\text {HER 2:342 }}$, an Affibody-based conjugate for in vivo imaging of HER2 expression in malignant tumors. J Nucl Med 47: 846-853, 2006.

19. Oriuchi N, Higuchi T, Hanaoka H, Iida Y and Endo K: Current status of cancer therapy with radiolabelled monoclonal antibody. Ann Nucl Med 19: 355-365, 2005.

20. Leonard JP, Siegel JA and Goldsmith SJ: Comparative physical and pharmacologic characteristics of iodine-131 and yttrium-90: implications for radioimmunotherapy for patients with nonHodgkin's lymphoma. Cancer Invest 21: 241-252, 2003.

21. Riccabona G and Decristoforo C: Peptide targeted imaging of cancer. Cancer Biother Radiopharm 18: 675-687, 2003.

22. Robinson MK, Doss M, Shaller C, Narayanan D, Marks JD, Adler LP, Gonzalez Trotter DE and Adams GP: Quantitative immuno-positron emission tomography imaging of HER2positive tumor xenografts with an iodine-124 labelled antiHER2 diabody. Cancer Res 15: 1471-1478, 2005.

23. Tolmachev V, Orlova A and Lundqvist H: Approaches to improvement of cellular retention of radiohalogen labels delivered by internalizing tumor targeting proteins and peptides. Curr Med Chem 10: 2447-2460, 2003

24. Bruskin A, Sivaev I, Persson M, Lundqvist H, Sjöberg S and Tolmachev V: Radiobromination of monoclonal antibody using isothiocyanato derivative of closo-dodecaborate $\left(\left[{ }^{76} \mathrm{Br}\right] \mathrm{Bromo}-\right.$ DABI). Nucl Med Biol 31: 205-211, 2004.

25. Orlova A, Bruskin A, Sivaev I, Sjöberg S, Lundqvist $\mathrm{H}$ and Tolmachev V: Radioiodination of monoclonal antibody using isothiocyanato derivative of closo-dodecaborate ([ $\left.{ }^{125} \mathrm{I}\right]$ IodoDABI). Anticancer Res 26: 1217-1224, 2006.

26. Persson M, Sivaev I, Winberg KJ, Malmström PU and Tolmachev V: In vitro evaluation of two polyhedral boron anion derivatives as linkers for attachment of radioiodine to the antiHER2 monoclonal antibody trastuzumab. In: Antibody Mediated Radionuclide Targeting of HER-2 for Cancer Diagnostics and Therapy: Preclinical Studies. Persson M (ed). Digital Comprehensive Summaries of Uppsala Dissertations from the Faculty of Medicine, ISSN 1651-6206, 140, 2006.

27. Koziorowski J, Henssen C and Weinreich R: A new convenient route to radioiodinated N-succinimidyl 3-and 4-iodobenzoate, two reagents for iodination of proteins. Appl Radiat Isot 49: 955-959, 1998.

28. Sivaev IB, Bruskin A, Nesterov VV, Antipin MY, Bregadze VI and Sjoeberg S: Synthesis of Schiff bases derived from the ammoniaundecahydro-closo-dodecaborate(1-) anion, $\left[\mathrm{B}_{12} \mathrm{H}_{11} \mathrm{NH}: \mathrm{CHR}\right]^{-}$, and their reduction into monosubstituted amines $\left[\mathrm{B}_{12} \mathrm{H}_{11} \mathrm{NH}_{2} \mathrm{CH}_{2} \mathrm{R}\right]^{-}$: a new route to water soluble agents for BNCT. Inorg Chem 38: 5887-5893, 1999.

29. Sundberg AL, Blomquist E, Carlsson J, Steffen AC and Gedda L: Cellular retention of radioactivity and increased radiation dose. Model experiments with EGF-dextran. Nucl Med Biol 30: 303-315, 2003.

30. Zidan J, Dashkovsky I, Stayerman C, Basher W, Cozacov C and Hadary A: Comparison of HER-2 overexpression in primary breast cancer and metastatic sites and its effect on biological targeting therapy of metastatic disease. Br J Cancer 93: 552-556, 2005.

31. Weissleder R: Molecular imaging in cancer. Science 312: 1168-1171, 2006.

32. Orlova A, Bruskin A, Sjöström A, Lundqvist H, Gedda L and Tolmachev V: Cellular processing of ${ }^{125} \mathrm{I}$ and ${ }^{111} \mathrm{In}$ labelled epidermal growth factor (EGF) bound to cultured A431 tumor cells. Nucl Med Biol 27: 827-835, 2000.

33. Behr TM, Gotthardt M, Barth A and Behe M: Imaging tumors with peptide-based radioligands. Q J Nucl Med 45: 189-200, 2001.

34. Reist CJ, Archer GE, Wikstrand CJ, Bigner DD and Zalutsky MR: Improved targeting of an anti-epidermal growth factor receptor variant III monoclonal antibody in tumor xenografts after labelling using N-succinimidyl 5-iodo-3-pyridinecarboxylate. Cancer Res 57: 1510-1515, 1997.

35. Vaidyanathan G, Affleck DJ, Bigner DD and Zalutsky MR: Improved xenograft targeting of tumor-specific anti-epidermal growth factor receptor variant III antibody labelled using Nsuccinimidyl 4-guanidinomethyl-3-iodobenzoate. Nucl Med Biol 29: 1-11, 2002.

36. Foulon CF, Welsh PC, Bigner DD and Zalutsky MR: Positively charged templates for labelling internalizing antibodies: comparison of $\mathrm{N}$-succinimidyl 5-iodo-3-pyridinecarboxylate and the D-amino acid peptide KRYRR. Nucl Med Biol 28: 769-777, 2001. 
37. Shankar S, Vaidyanathan G, Affleck DJ, Peixoto K, Bigner DD and Zalutsky MR: Evaluation of an internalizing monoclonal antibody labelled using N-succinimidyl 3-[131I]iodo-4phosphonomethylbenzoate ([131I]SIPMB), a negatively charged substituent bearing acylation agent. Nucl Med Biol 31: 909-919, 2004

38. Stein R, Govindan SV, Mattes MJ, Shih LB, Griffiths GL, Hansen HJ and Goldenberg DM: Targeting human cancer xenografts with monoclonal antibodies labelled using radioiodinated, diethylenetriaminepentaacetic acid-appended peptides. Clin Cancer Res 5 (suppl 10): 3079-3087, 1999.

39. Govindan SV, Griffiths GL, Stein R, Andrews P, Sharkey RM, Hansen HJ, Horak ID and Goldenberg DM: Clinical-scale radiolabelling of a humanized anticarcinoembryonic antigen monoclonal antibody, hMN-14, with residualizing 131I for use in radioimmunotherapy. J Nucl Med 46: 153-159, 2005.

40. Tolmachev V and Sjöberg S: Polyhedral boron compounds as potential linkers for attachment of radiohalogens to targeting proteins and peptides. Collect Czech Chem Commun 67: 913-935, 2003.

41. Wilbur DS, Hamlin DK, Srivastava RR and Chyan MK: Synthesis, radioiodination, and biodistribution of some nidoand closo-monocarbon carborane derivatives. Nucl Med Biol 31: 523-530, 2004

42. Wilbur DS, Chyan MK, Hamlin DK, Kegley BB, Risler R, Pathare PM, Quinn J, Vessella RL, Foulon C, Zalutsky M, Wedge TJ and Hawthorne MF: Reagents for astatination of biomolecules: comparison of the in vivo distribution and stability of some radioiodinated/astatinated benzamidyl and nido-carboranyl compounds. Bioconjug Chem 15: 203-223, 2004.
43. de Jong M, Barone R, Krenning E, Bernard B, Melis M, Visser T, Gekle M, Willnow TE, Walrand S, Jamar F and Pauwels S: Megalin is essential for renal proximal tubule reabsorption of ${ }^{11}$ In-DTPA-octreotide. J Nucl Med 46: 1696-1700, 2005.

44. Nestor M, Persson M, Cheng J, Tolmachev V, van Dongen G, Anniko $\mathrm{M}$ and Kairemo K: Biodistribution of the chimeric monoclonal antibody U36 radioiodinated with a closododecaborate-containing linker. Comparison with other radioiodination methods. Bioconjug Chem 14: 805-810, 2003.

45. Tolmachev V, Koziorowski J, Sivaev I, Lundqvist H, Carlsson J, Orlova A, Gedda L, Olsson P, Sjoberg S and Sundin A: Closododecaborate(2-) as a linker for iodination of macromolecules. Aspects on conjugation chemistry and biodistribution. Bioconjug Chem 10: 338-345, 1999.

46. Adams GP, McCartney JE, Tai MS, Oppermann H, Huston JS, Stafford WF III, Bookman MA, Fand I, Houston LL and Weiner LM: Highly specific in vivo tumor targeting by monovalent and divalent forms of 741F8 anti-c-erbB-2 singlechain Fv. Cancer Res 53: 4026-4034, 1993.

47. Tai MS, McCartney JE, Adams GP, Jin D, Hudziak RM, Oppermann H, Laminet AA, Bookman MA, Wolf EJ and Liu S: Targeting c-erbB-2 expressing tumors using single-chain Fv monomers and dimers. Cancer Res 55: 5983s-5989s, 1995.

48. Adams GP, Schier R, McCall AM, Crawford RS, Wolf EJ, Weiner LM and Marks JD: Prolonged in vivo tumour retention of a human diabody targeting the extracellular domain of human HER2/neu. Br J Cancer 77: 1405-1412, 1998. 